\title{
Slotted Reinforced Concrete Beam-Column Connection: A State-of-the-Art Review
}

\author{
Mohamed A. Sakr, Tarek M. Khalifa, and Mina M. Soliman \\ Structural Engineering, Faculty of Engineering, Tanta University, Tanta, Egypt. \\ Email: mohamed.sakr2@f-eng.tanta.edu.eg, tarek.khalifa@f-eng.tanta.edu.eg, Mina Medhat@f-eng.tanta.edu.eg.
}

\begin{abstract}
Research on reinforced concrete (RC) beam-column connections has significantly increased during the past few decades. Interest in this topic is related to the importance of beam-column connections in maintaining the integrity of the whole structure. The slotted RC beam-column connection was investigated as a promising low damage beam-column connection replacement for conventional design. A slotted $\mathrm{RC}$ beam consists of a conventional $\mathrm{RC}$ beam, modified with a narrow vertical slot adjacent to the face of the column that runs approximately threequarters of the beam depth. This study reviews the literature on the mechanics and design of slotted beams, illustrating the works of various researchers on developing and modifying this innovative system. Then, the research progress in the behavior of slotted RC beams is briefly described, in chronological order, to place each contribution in a wider context. Extremely promising structural performance was observed due to minimum beam elongation, non-tearing action, minimum cracks, high energy dissipation, and stable hysteresis response. At the end of the study, a list of the main gaps that need further investigation and recommendations to fill out these gaps are provided.
\end{abstract}

Keywords- Slotted, beam-column, connection, low cyclic fatigue, low damage, plastic hinge relocation, review.

\section{INTRODUCTION}

Last earthquake investigations and subsequent laboratory works have shown that beam-column connections have a key role in reinforced concrete (RC) structures, as it is responsible for determining the strength degradation and ductile/nonductile behavior of moment-resisting frame, maintaining the integrity of the whole structure. Fig.1 shows the failure of beam-column connections, which can result in structural collapse [1, 2].

Since the 1970s, reinforced concrete moment resisting frame design has been based upon Capacity Design Philosophy, which aims to prevent building collapse by ensuring the formation of a ductile beam-sway mechanism (Park and Paulay [3]).

This is done by detailing ductile plastic hinge zones in beams and allocating reserve capacity to other elements such that they remain elastic. While last earthquakes have demonstrated that Capacity Design Philosophy is successful in avoiding total structural collapse, they have also emphasized the extensive damage that happens in yielding plastic hinges. In some cases, the structural damage was too costly to repair and had to be torn down $[4,5]$.

In addition to undergoing extensive damage, plastic hinge zones at beam ends are known to elongate during cyclic deformations. As indicated in Fig. 2, two contributions are commonly recognized for beam elongation: firstly, the 'geometrical contribution' caused by rotation of a finite-depth beam about the neutral axis depth, and secondly, the 'material contribution' caused by residual tensile steel strains. Numerous investigations have shown this elongation can range between $2-5 \%$ of the beam depth [6-9], which in turn causes:

1) Column hinging $[10,11]$.

2) Loss of diaphragm action [12].

3) Tearing of floor slab [13].

4) Unseating failure of floor slab [14].

In light of this, there has been an increasing need to develop structural systems with high ductility capacity and can withstand severe earthquake motions with minor damage to minimize repair and business closure costs after an earthquake.

The slotted beam-column connection is a solution for the abovementioned issues. Palmieri et al. [15] first proposed the concept during the PRESSS research program in the form of a UT-GAP connection in 1996, as shown in Fig.3, and a TCYGap connection (Priestley et al. [16]).

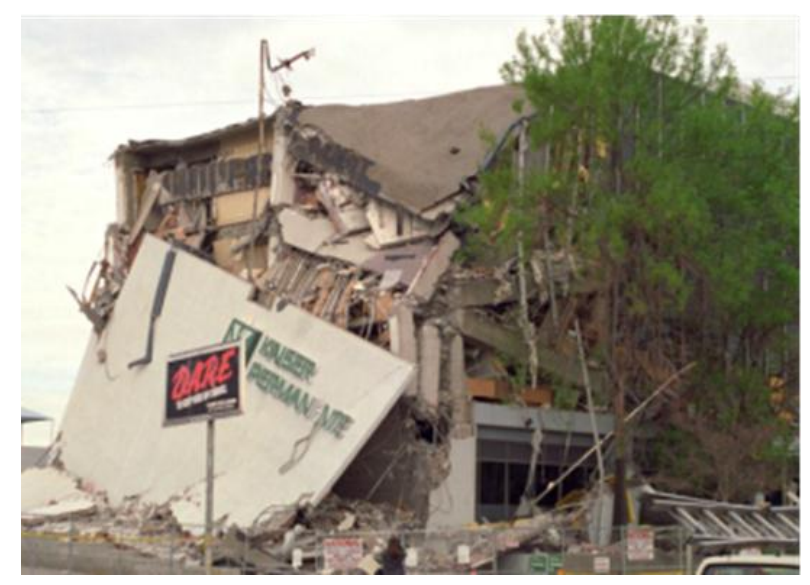

Figure 1. Structure collapse because of failure of deficient beam-column joints, Kaiser Permanente Building, Northridge earthquake, 1994.

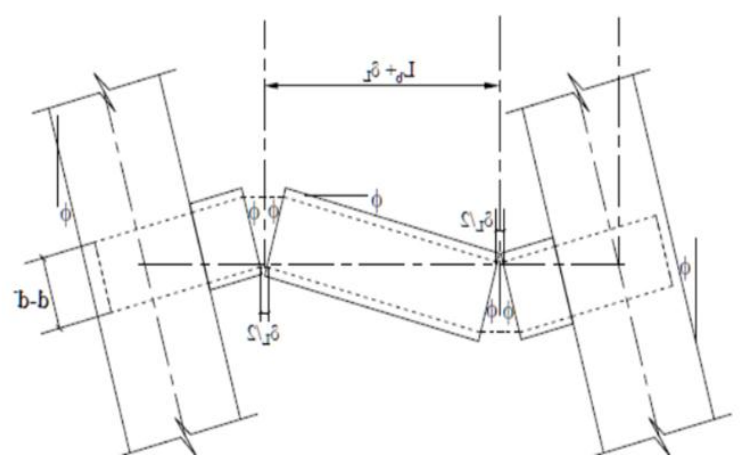

Figure 2. Schematic of the geometric beam elongation mechanism. 


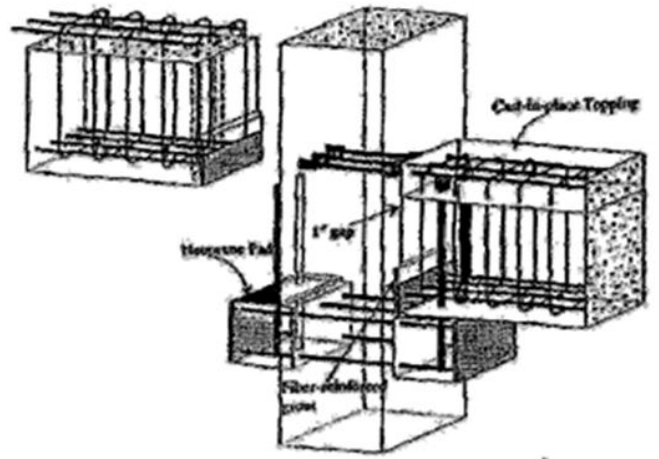

Figure 3. Specimen UT-GAP [15].

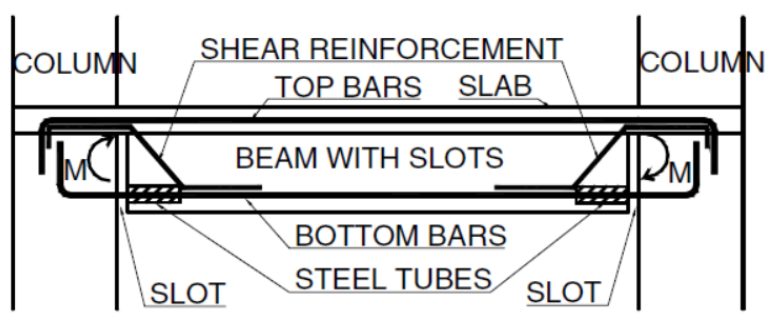

Figure 4. Early Japanese slotted reinforced concrete beam (Ohkubo et al. [18]).

UT-GAP connection provided a one-inch gap between the beam and column face, over three-quarters of the beam depth at the column face, which in turn forced rotation to occur about the bottom of the beam, constraining plasticity to the top longitudinal reinforcement. This connection was developed to include post-tensioning to provide a more direct force transfer. Despite the beam elongation being reduced, the floor diaphragm was likely to be damaged due to the gap opening at the top of the beam.

At a similar time in Japan, Matsuoka \& Ohkubo [17] proposed the slotted beam for in-situ reinforced concrete in 1996. Ohkubo et al. [18] had examined a new resisting mechanism known as a slotted beam. It consists of a conventional RC beam, modified with a narrow vertical slot adjacent to the column's face, as shown in Fig. 4, where the yielding is restricted to only the lower reinforcement RFT and cracking and crushing of the concrete is minimized. It was investigated as a promising non-tearing floor replacement for traditional design.

\section{MECHANICS AND DESIGN OF SLOTTED REINFORCED CONCRETE BEAM-COLUMN CONNECTION}

\section{A. Bottom Longitudinal Reinforcement for Flexural Strength}

The slotted beam's flexural response is only governed by the bottom longitudinal RFT. Flexural forces induced in diagonal shear RFT have little influence because they are close to the neutral axis which located in the top hinge [18], as illustrated in Fig. 5. Therefore, the nominal flexural strength, Mn, can be calculated, as given in Equations (1) and (2), respectively.

$$
M_{n}^{+}=A_{s} f_{y}\left(d-\frac{a}{2}\right)
$$

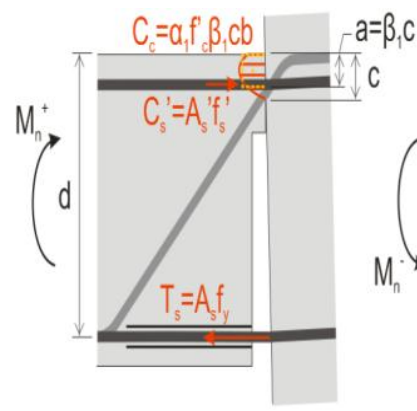

(a)

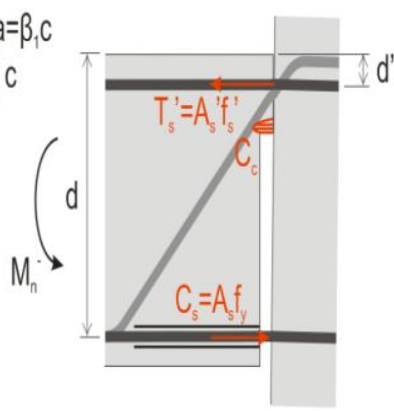

(b)
Figure 5. Evaluation of nominal flexural strength for slotted beams. (a) Positive (gap opening) moment, and (b) Negative (gap closing) moment[19].

$$
M_{n}{ }^{-}=A_{s} f_{y}\left(d-d^{\prime}\right)
$$

Where:

Mn is the nominal flexural strength, $A_{s}$ and $A_{s}{ }^{\prime}$ is the area of the bottom and top RFT, $f_{y}$ is the yield strength of the bottom RFT, $d$ is the effective beam depth, a is the Whitney equivalent rectangular concrete stress block depth, $d^{\prime}$ is the depth to the top reinforcement, $f_{s}{ }^{\prime}$ is the strength of the top RFT, $C_{c}$ is the compression force in the concrete, $C_{s}$ and $C_{s}{ }^{\prime}$ is the compression force in the bottom and top RFT, $T_{s}$ and $T_{s}{ }^{\prime}$ is the tension force in the bottom and top RFT.

\section{B. Top longitudinal Reinforcement for Crack and Elongation Control}

Top longitudinal reinforcement does not need to be sized for the flexural demand as previously mentioned; however, it needs to be sized to remain elastic in order to keep the neutral axis in the top hinge, which in turn limits cracking and elongation through the concrete top hinge.

AU [19] carried out a parametric study on the top-to-bottom reinforcement ratio, As'fy'/Asfy. A ratio between 2.0 and 2.5 can be regarded as an acceptable guide for design.

\section{Shear Transfer Mechanism}

The slot next to the column face prohibits the diagonal struts from entering into the beam-column joint. Therefore, other shear transfer mechanisms had to be developed for the slotted $\mathrm{RC}$ beams.

Ohkubo et al. [18] first studied the shear transfer mechanism and successfully used diagonal RFT in slotted beams. This guarantees that shear forces are transferred through the hanger's axial deformations rather than dowel action. Dowel action necessitates excessive deformation, which leads to unwanted shear sliding. The nominal shear strength, Vs, can be calculated as given in Equation (3).

$$
V_{s}=A_{V} f_{y t} \operatorname{Sin} \theta_{h}
$$

Where:

Vs is the nominal shear strength provided by the diagonal RFT, $\mathrm{Av}$ and $f_{y t}$ are the area and the lower characteristic yield strength of diagonal RFT, respectively, and $\Theta_{h}$ the inclination of the diagonal RFT from horizontal. 


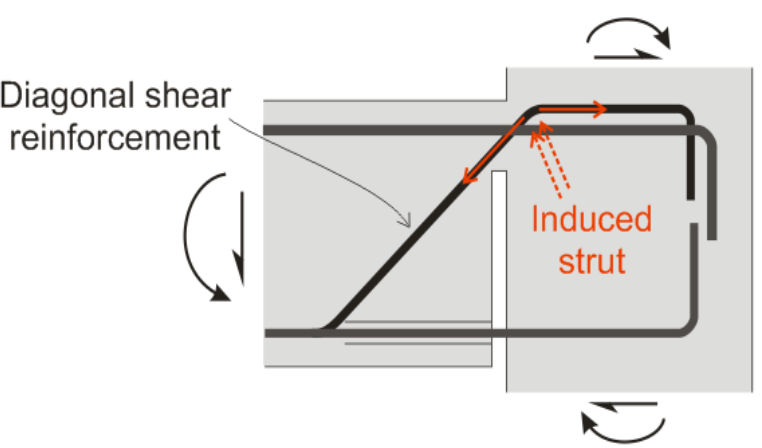

Figure 6. Diagonal shear RFT [19].

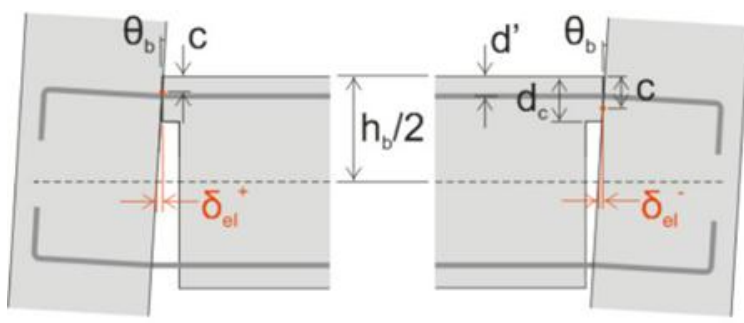

Figure 7. Beam elongation for slotted beam [19].

In addition to Ohkubo et al recommendations, AU [19] stated that the upper bend in the diagonal RFT should be well located within the column to capture the induced strut, as shown in Fig. 6.

\section{Beam Elongation}

One of the main advantages of slotted beams over monolithic beams is that they have minimal beam elongation. This significantly reduces damage to surrounding floor slabs, ensuring that diaphragm action is preserved during earthquakes. Beam elongation is minimized due to the accommodation of end-rotations via closing and opening of the slot, as shown in Fig. 7.

As previously mentioned, 'material contribution' and 'geometrical contribution' are the two contributions to beam elongation in the monolithic beam. However, they have little effect in slotted beam because its behavior is only governed by compression tension yielding of the bottom RFT. The very minimal yielding of top RFT limits the 'material contribution', and the rotation about a shallow concrete top-hinge minimizes the 'geometric contribution'. Elongation of slotted beam $\delta_{e l, \text { total }}$ can be calculated as given in Equation (4).

$$
\delta_{e l, \text { total }} \leq \theta_{b} d_{c}
$$

Where:

$\delta_{e l, \text { total }}$ is the elongation of the slotted beam, $\theta_{b}$ is the inclination of the concrete top-hinge from vertical, and $d_{c}$ is the depth of the concrete top-hinge.

AU [15] observed that a slotted beam would only exhibit $1 / 8$ th to $1 / 10$ th of the beam elongation observed in conventional monolithic beams. Whilst literature recognizes beam elongation in monolithic beams to be of the order of 2$5 \%$ of the beam depth [6-9].

\section{E. Longitudinal Bar Buckling}

Bottom longitudinal RFT bars are more susceptible to buckling in slotted beams than in monolithic beams because bars are subject to extensive deformations in compression in slotted beams. Any buckling of bottom bars will result in severe strength degradation because the strength of a slotted beam is derived from the yielding of this reinforcement. Also, it may result in bar fracture on subsequent tensile excursions because of the high bending strains induced at the edges of the bar from buckling. It is therefore essential to prevent buckling to ensure the survival of the connection during an earthquake.

Experimental investigations were conducted to study the buckling mechanism. Buckling was observed mainly along the unbonded length directly adjacent to the slot. The beam moved downwards relative to the column under a downwards vertical shear. As the bar was forced to bend downwards as it entered the debonding tube, this caused a little curved eccentricity along the unbonded length, as shown in Fig. 8-a. As the slot closed more, the eccentricity initiated buckling along the unbonded length, causing spalling of the beam soffit, as shown in Fig. 8-b.

Through experimental investigations, it was observed that buckling would occur in the first stirrup spacing next to the slot if the stirrup spacing is large, and a higher buckling mode may occur, which extends across multiple stirrups along the unbonded length if the stirrup spacing is small [15]. In addition, buckling may extend out into the slot if the tie immediately adjacent to the slot is not strong enough, as observed in investigations carried out by Leslie [20].

The existing stirrup spacing provisions were found to be insufficient to avoid buckling of bottom longitudinal reinforcement in slotted beams, as observed in experimental investigations. To prevent these bars from buckling, additional restraint must be provided in the region along the unbonded length of the bottom bars.

Accordingly, AU [19] investigated two methods to restrain buckling. The first method was to reduce the stirrup spacing to $3 d_{b}$, and the second method was to reduce the spacing to $4 d_{b}$ and provide additional support to longitudinal RFT bars along the unbonded length by debonding using steel tubes where $d_{b}$ is the bar diameter. The second method was shown to be more effective in preventing soffit spalling and buckling. Decreasing the stirrup spacing only was insufficient because the bar buckled at a higher mode - that is, across multiple stirrup spacings. Increasing the flexural stiffness of the steel tube helped to restrain this higher mode buckling. Eventually, AU recommended provisions for the slotted beam as illustrated below in Fig. 9. Additional research is needed to determine the proper stirrups' size for a variety of cases. The steel tube ought to be thick enough to resist buckling itself, and the internal diameter should minimize the clearance between the bar and tube.

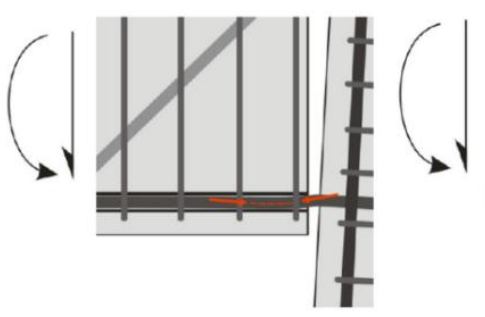

(a)

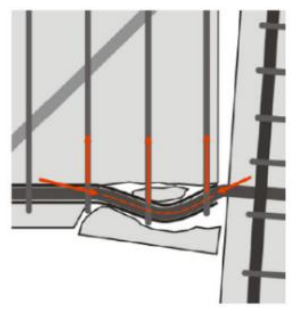

(b)
Figure 8. Buckling mechanism in bottom longitudinal reinforcement.

(a) Slight eccentricity from vertical movement, and (b) Buckling resulting in spalling [19]. 


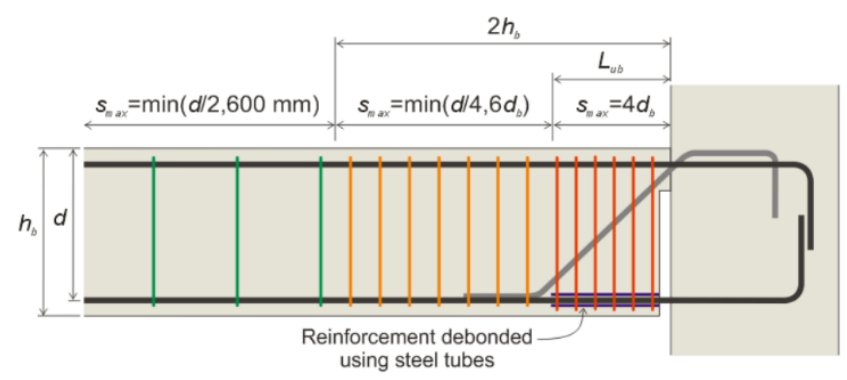

Figure 9. Recommended maximum stirrup spacings for anti-buckling in slotted beams[19].

Too much clearance allows the bar to buckle within the tube, resulting in an eccentricity that may cause the tube to buckle as well. More research is needed to establish the proper tube wall thickness for a variety of cases.

\section{F. Low Cycle Fatigue}

In conventional RC beams, Longitudinal bars yield considerably in tension compared to compression. Bottom reinforcement, on the other hand, yields extensively in both tension and compression in slotted beams. As a result, the connection is more at risk of low-cycle fatigue failure due to bottom RFT fracture when it is subjected to tension. To reduce the total accumulated plastic strain, a length of the bottom longitudinal reinforcement is unbonded.

AU [19] conducted a parametric study on numerical fullscale slotted and conventional beam-column connections. The reinforcement ratio and beam depth were changed in the multispring connection so that each beam had the same moment capacity.

The study showed that the plastic strain accumulation in slotted beams was 2-3 times more than in a conventional connection, and the damage accumulation decreased as the reinforcement ratio was increased. This is due to the fact that, for a given moment capacity, the beam depth can be reduced when the reinforcing area is increased. Yielding reinforcement is closer to the neutral axis in shallower beams, resulting in reduced strains. To guarantee acceptable low cycle fatigue resistance for slotted beams, a minimum reinforcement ratio of 0.006 to 0.008 appears reasonable.

Through investigations, it was observed that the unbonded length should be maximized to enhance low cycle fatigue performance. The unbonded length is solely limited by the fact that it must end before the bottom bend in the diagonal hanger reinforcement. As a result, the maximum unbonded length for $45^{\circ}$ diagonal reinforcement is likely to range between $0.9(\mathrm{~d}-\mathrm{d}$ ') and d-d'.

\section{RELOCATION OF PLASTIC HINGE}

In recent decades, several plastic hinge relocation techniques have been developed to eliminate transverse steel congestion at the joint, prevent strain penetration into the joint, and keep strong-column weak-beam behavior. This is achieved by special detailing of the steel reinforcement (Paulay and Priestley [21]), increasing the beam depth at the face of the column (Haunch), and installing web-bonded FRP sheets on the concrete beam near the column face (Mahini and Ronagh [22]).

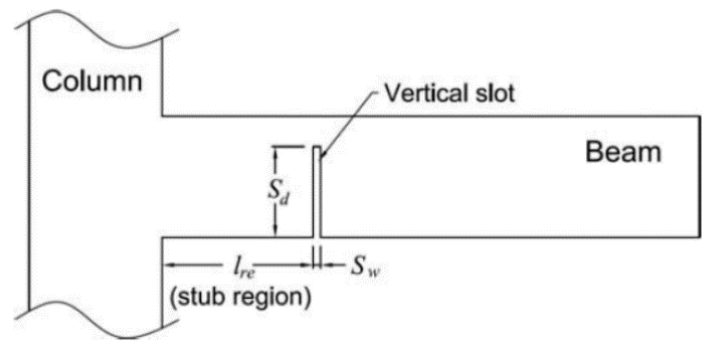

Figure 10. Schematic of the slotted beam-column connection with relocated plastic hinges $[23,24]$.

The major disadvantage of the aforementioned relocation techniques is the high level of inaccuracy in determining the location of the center of rotation which in turn leads to inaccurate prediction of the drift capacity of the structure.

Oudah and El-Hacha [23, 24] succeeded in relocating the plastic hinge in the slotted beam-column connection to enhance the performance of the connection and improve

accuracy in determining the location of the center of rotation by moving the vertical away from the face of the column, as shown in Fig. 10.

Two specimens were experimentally tested: one with a vertical slot at the face of the column and the other with a vertical slot at a distance equal to the spacing between the top and bottom RFT. The results of this experimental evaluation showed that the plastic hinge was achieved successfully by examining the curvature distribution along with the beam and load-deformation behavior. It was also found that relocating the plastic hinge away from the face of the column spreads the plasticity over a longer distance by observing the crack pattern at failure and yields a force transfer mechanism in the joint similar to that in conventional connections. It was also observed that the optimum relocation distance is equivalent to the effective shear depth in the single slotted beam-column connection. In the double slotted beam-column connection, there is no optimal plastic hinge relocation distance. Instead, the relocation distance should be designed to strike a balance between drift capacity and drift demand.

\section{DOUBLE SLOTTED REINFORCED CONCRETE BEAM-COLUMN CONNECTION}

After several investigations on single slotted beams (SSB), Oudah and El-Hacha [25, 26] suggested the application of double-slotted beams (DSB), which consisted of two vertical slots made into the bottom and the top sides of the beam member, as illustrated in Fig. 11. A Large amount of diagonal reinforcement was placed in the concrete hinge to enhance the shear resistance and prevent sliding shear failure. The diagonal reinforcement is designed to stay elastic during the plastic rotation of the beam. The top and the bottom reinforcements act as energy dissipation devices as they both yield in compression and tension.

The performance of DSB systems as well as the effect of the slot location on the damage patterns, were studied, see Fig. 12. Three large-scale connections were tested and examined using FEM simulation. It was found that the DSB systems succeeded in reducing beam elongation, achieving a nontearing action, higher drift capacity, and minimal repair. 


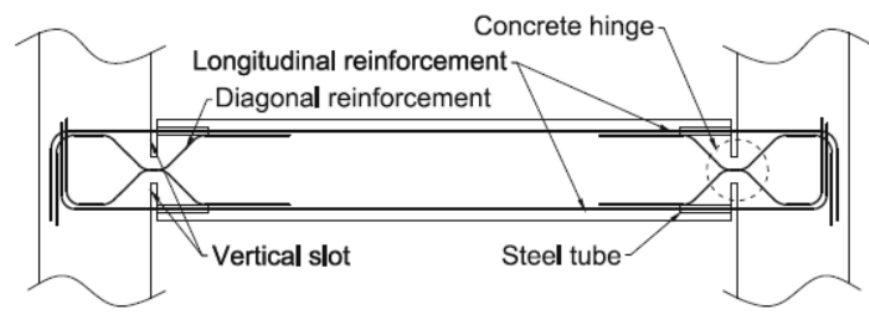

Figure 11. Schematic of the DSB system.

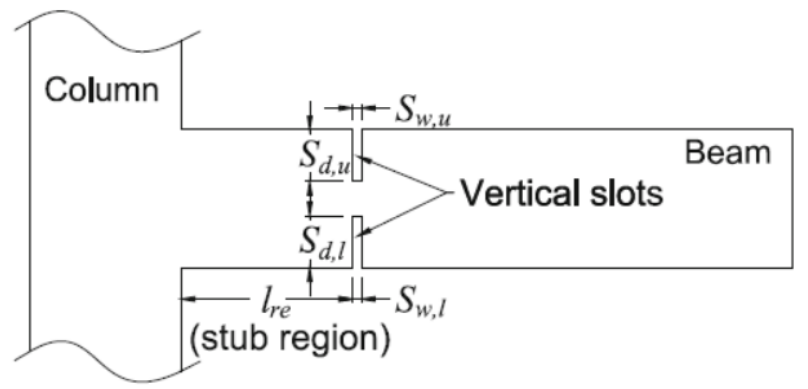

Figure 12. Schematic of the DSB system with relocated plastic hinges.

The plastic hinges were not only successfully relocated with an accurate prediction of the center of rotation but also prevented bond degradation and extensive cracking at the joint. The formation of the joint shear deformation mechanism is similar to that in conventional $\mathrm{RC}$ frames but with less shear demand.

\section{RESEARCH PROGRESS IN THE BEHAVIOR OF SLOTTED REINFORCED CONCRETE BEAM-COLUMN CONNECTION}

Ohkubo and Hamamoto [27] compared the performance of two single slotted interior beam-column connections with floor slabs under cyclic loading to that of a conventional interior beam-column connection with the same ultimate flexural strength. The slotted beam connection response is stable and did not show any signs of pinching shear when compared to the conventional connection response, which experienced pinching shear early under cyclic loading. As a result, the former dissipates more energy than the latter for the same drift ratio. A remarkable reduction in the crack number and size is also observed in the slotted connections, proving the system's non-tearing action. In addition, when compared to a conventional connection, the elongation of the beam in the slotted connection was negligible.

$\mathrm{Au}$ [19] made significant progress in the design and behavior of single slotted beam-column connections. The flexural mechanism, the shear mechanism, and the design considerations were all thoroughly investigated. The system's behavior was confirmed by both experimental testing and analytical analysis. One interior and one exterior single slotted connection were tested under cyclic loading. The exterior connection showed a stable hysteretic response up to a $3.5 \%$ drift; after that, the bottom reinforcement fractured. During the test, minimal cracking and concrete spalling were observed. In contrast to the exterior connection, the interior connection showed a less stable hysteretic response and pinching shear at $2.5 \%$ drift because of the slippage of the bottom reinforcement and the strain penetration into the joint. It was also observed that the ultimate drift ratios of both connections are low, so further research is needed to achieve higher drift ratios. To predict the flexural response of the connections, a simple analytical model and a multi-spring model were also developed. The models showed satisfactory results when compared with the experimental behavior and were used to perform sensitivity analyses.

Byrne and Bull [28] investigated the behavior of two interior single slotted beam-column connections. The two specimens were designed according to the recommendations of $\mathrm{Au}$ [19] and the NZS 3101-1. (2006) code and tested under cyclic loading. The specimens showed a stable hysteretic response and dissipated a high amount of energy without any signs of pinching shear. At a drift ratio of $5.5 \%$, the specimens failed due to the bottom steel reinforcement fracture caused by the low cycle fatigue effect. The top reinforcement remained elastic up to $3.5 \%$ drift, resulting in a total beam elongation of $0.7 \%$, which is less than the $2-5 \%$ observed in monolithic connections [7, 29]. The effective column depth recommended by $\mathrm{Au}$ [19] was reduced, as were the joint shear requirements.

Muir et al. conducted a research project, consisted of two phases. In Phase I, a two-story, two-by-one bay, reinforced concrete single slotted beam-column connections superassembly was tested under quasi-static cyclic loading at the University of Canterbury [30-32]. The superassembly owed the system's excellent performance when subjected to earthquake-like motion in terms of damage, and minimal residual consisted of precast floor members attached to 3D single slotted beam-column connections, as shown in Fig.13. The system and the loading configurations of the superassmbely allowed the interaction between flexure, shear, and torsion. Test results showed the system's excellent performance when subjected to earthquake-like motion in terms of damage and minimal residual drift. It was observed that the diagonal reinforcement was heavily loaded, and the floors also acted as a constraint on beam elongation, causing compressive stresses in the beams and tension forces in the floors. Fewer and smaller cracks were also observed in the slotted system when compared to conventional connections. In phase II, two portions of the superassembly specimen were extracted for further testing after Phase one testing was completed $[33,34]$. There were three reasons for putting these to the test. Firstly, determining the connection's residual capacity is a critical consideration when evaluating a structure for future use after a large earthquake. Secondly, to develop methods for retrofitting the slotted beam-column connection if the residual capacity is insufficient or if the building's use changes necessitating an upgrade.

Finally, to evaluate the performance of external and replaceable dampers for retrofit and new construction scenarios.

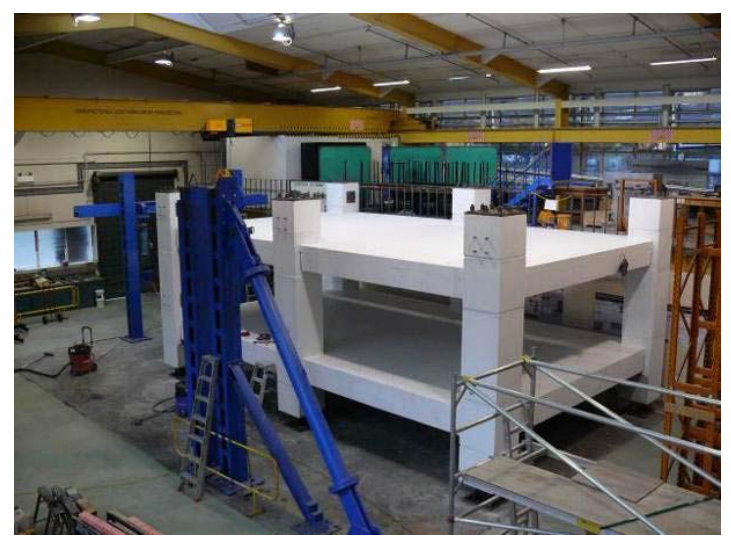

Figure 13. Experimental setup perspective of Phase one[30]. 
During Phase II, five tests were carried out under the same loading protocol used in Phase I. To evaluate the residual capacity, SA2 and three, which were extracted from the superassembly were tested in their original state. SA2 was retrofitted after being tested to destruction. Fabricated cleats were fastened to the beam soffit and column face using epoxied rods to facilitate rapid attachment of external dampers. Tension-compression yielding (TCY), sliding friction (SFD), and high force-to-volume (HF2V) external dampers were all examined, as shown in Fig.14.

The overall performance was extremely promising. SA2 and 3 completed the loading protocol with a stable response and high energy dissipation until failure through low cycle fatigue was realized. SA2-TCY displayed a very similar response to SA2 and three due to the similarity in the energy dissipation methods, SA2-SFD also displayed a stable response and similar levels of energy dissipation to SA2, and SA2-HF2V displayed extremely high levels of damping and stable response throughout loading. No significant new cracking was observed during the testing of any of the specimens. The elongation of Beam was also minimal. Torsional deformation of the beams was likewise very small because of the effectiveness of the three-hanger detail. In general, the retrofitting techniques performed very well. However, further care must be taken to avoid the slippage between the steel cleat and the beam soffit.

Alper Aldemir [38] investigated the effect of the slot depth on the behavior of double-slotted RC beam (DSB) systems under monotonic loading by using finite element analysis. A parametric study was conducted, the slot depth/beam height ratio was changed, and there were no changes in the geometrical properties and reinforcement details in the analyses. The displacement, load, and rotation capacities of DSB systems were compared to classify models' performance.
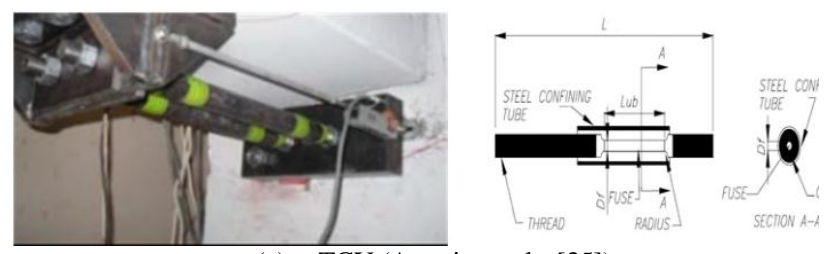

(a) TCY (Amaris, et al. [35]).
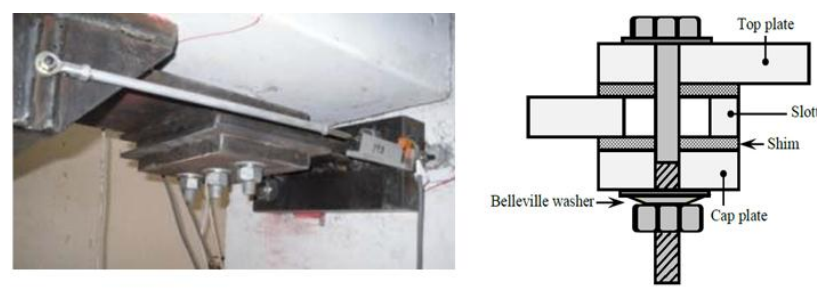

(c) SFD (Chanchi Golondrino, et al. [36]).
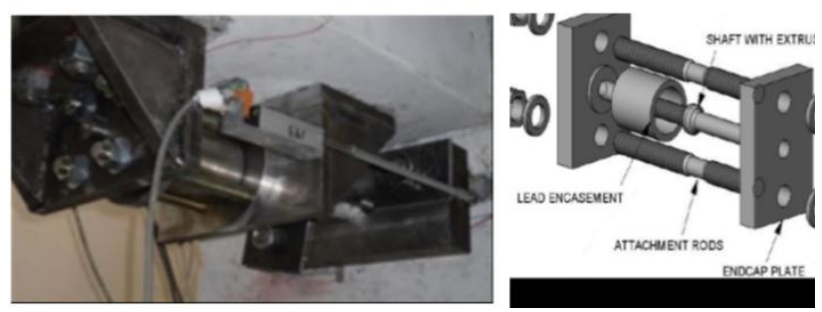

(e) HF2V (Rodgers [37]).

Figure 14. Dampers tested.
As a consequence, it was observed that for each slot location, the slot depth/beam height ratio of 0.3 performed better.

Oudah and El-Hacha [39] proposed using shape memory alloy (SMA) at the plastic hinge region in the single slotted beam-column connections to use its self-centering advantage. The innovative design was based upon placing the shape memory alloy (SMA) bar at the bottom side of the beam, as illustrated in Fig. 15.

The self-centering behavior was attained under both negative and positive bending. Large-scale connections were experimentally tested under cyclic loading to investigate the performance of the innovative system. Test results indicated the superior behavior of the system in maintaining a selfcentering behavior, relocating the plastic hinge region away from the column's face, mitigating the pinching shear effect, and reducing joint distortion, as compared with conventional $\mathrm{RC}$ connections. Therefore, it was concluded that the proposed design has a high potential for reducing construction costs while achieving excellent super-elastic performance. It was recommended to use trained SMA bars to improve the damping properties and the cumulative energy dissipation. Future research should focus on improving the anchorage system to prevent the SMA bar from premature failure and further verifying the response under earthquake-like motion.

Oudah and El-Hacha [40] proposed and tested a monolithic SMA-reinforced double-slotted beam-column connections; the connection consisted of double vertical slots made away from the face of the column at a distance equal to the beam effective shear depth. The SMA reinforcement spanned the vertical slots, mechanically anchored in the concrete joint, and coupled with a set of diagonal reinforcements that were designed to resist beam shear force, as illustrated in Fig.16. In comparison to existing monolithic self-centering concrete beam-column connections, the new connection had two unique features: precise control of the location of the center of rotation and the ability to mitigate damage to concrete slabs attached to the beam member by using an expansion joint in the slab at the location of the beam's vertical slots. To investigate the connection response, a large-scale specimen was fabricated, instrumented, and tested.

Test results indicated the efficiency of the connection in achieving a self-centering response for drift ratios up to $14 \%$. The connection, on the other hand, experienced relatively low damping characteristics. To improve the connection response, the following design recommendations were made: use of smaller diameter SMA reinforcement; use of mechanically trained SMA material; and use of screw-lock free anchors.

Future research should also examine the connection's performance under real-time earthquake load to facilitate assessing the connection's dynamic response and the SMA bars' strain rate effect.

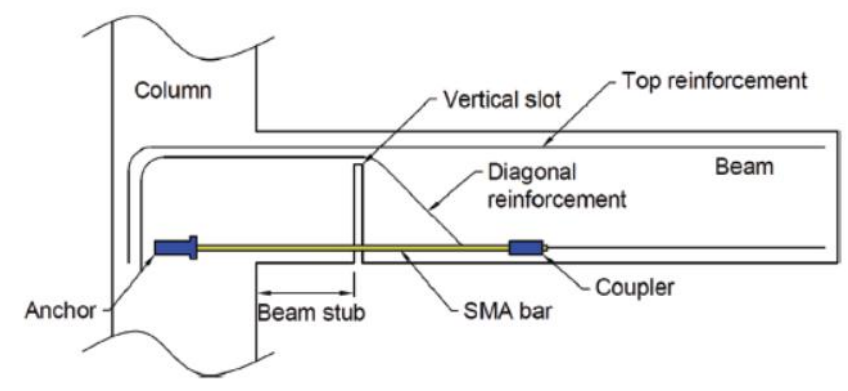

Figure 15. Schematic drawing of proposed plastic hinge detail [39]. 


\section{Column}

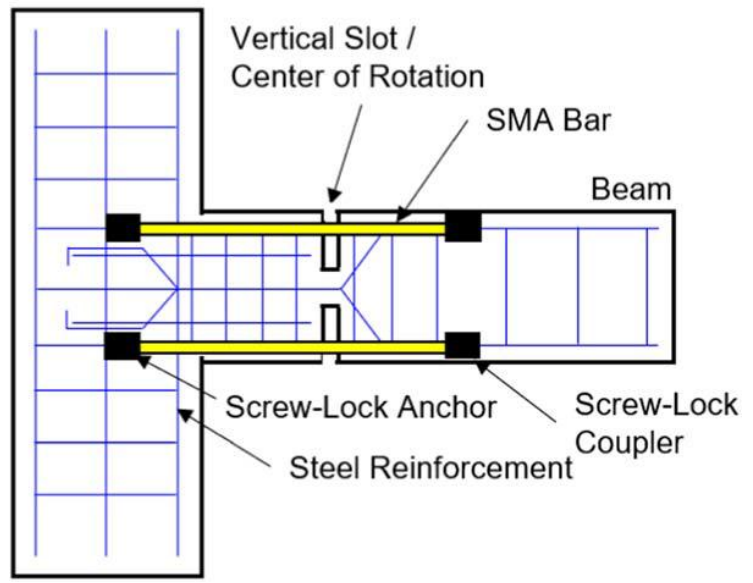

Figure 16. Proposed SMA-reinforced self-centering monolithic concrete connection [40].

Oudah and El-Hacha [41] investigated the deformation mechanisms and damage evolution of large-scale experimentally tested SSB and DSB connections with and without relocated vertical slots. The evolution of damage was investigated using ductility-based damage indices, energybased damage indices, and other forms of damage assessment methods. Using the Digital Image Correlation Technique (DICT), the contribution of the column deformation, joint deformation, and beam deformation to the overall drift was assessed. IT was recommended that the vertical slots in the SSB and DSB systems should be placed at a distance equal to the beam effective shear depth measured from the face of the column. The ductility, deformability characteristics, and energy dissipation of the beams under positive and negative bending are generally optimized at this recommended value.

\section{CONCLUSION}

The review work shows that the slotted reinforced concrete beam-column subassembly is a viable substitute for the conventional detail. Extremely promising structural performance was observed due to minimum beam elongation, non-tearing action, minimum cracks, high energy dissipation, and stable hysteresis response up to a $3.5 \%$ beam drift ratio. The review also highlights some gabs as follows:

- Slotted beams are more at risk to low cycle fatigue because of the plastic strain accumulation in bottom longitudinal reinforcement. This is clearly shown in the premature failure of the bottom bars. Additional effort is required to design the longitudinal beam reinforcement against buckling and low cyclic fatigue, and further research is needed to achieve higher drift ratios.

- Additional effort in the design stage is required to determine the proper stirrups' size for a variety of cases to prevent longitudinal bars from buckling.

- The steel tube ought to be thick enough to resist buckling itself, and the internal diameter should minimize the clearance between the bar and tube. Too much clearance allows the bar to buckle within the tube, resulting in an eccentricity that may cause the tube to buckle as well.
Additional effort is needed to establish the proper tube wall thickness for a variety of cases.

- Additional effort in the construction stage is needed to induce vertical slots in the beams and the slabs and install steel tubes.

- Deterioration of the bond between the bottom reinforcement and the concrete during positive and negative bending caused by yield penetration.

- Further research is required to develop the complex load transfer mechanism within the joint and the formation of diagonal cracks in the joint.

\section{References}

1.El-Amoury, T. and A.J.E.S. Ghobarah, Seismic rehabilitation of beamcolumn joint using GFRP sheets. 2002. 24(11): p. 1397-1407.

2.Tasligedik, A.S.A., Umut Kam, Weng Yuen Pampanin, tefano Strength hierarchy at reinforced concrete beam-column joints and global capacity. Journal of Earthquake Engineering, 2018. 22(3): p. 454-487.

3.Park, R. and T. Paulay, Reinforced concrete structures. 1975: John Wiley \& Sons.

4.Hall, J.F. and V.M. Challa, Beam-column modeling. Journal of engineering mechanics, 1995. 121(12): p. 1284-1291.

5.Matsumori, T. and S. Otani, Correlation of damage and analysis of $R / C$ building: Experience from the 1995 Kobe earthquake. Structural Engineering and Mechanics, 1998. 6(8): p. 841-856.

6.Restrepo, J., R. Park, and A. Buchanan, Seismic load tests on midspan connections between precast concrete beams. NZ Concrete Society, Technical Report TR10, 1990: p. 55-71.

7.Fenwick, R. and L. Megget, Elongation and load deflection characteristics of reinforced concrete members containing plastic hinges. Bulletin of the New Zealand Society for Earthquake Engineering, 1993. 26(1): p. 28-41.

8.Fenwick, R. and B. Davidson, Elongation in ductile seismic-resistant reinforced concrete frames. Special Publication, 1995. 157: p. 143-170.

9.Meggett, L. and R.J.B.o.t.N.Z.S.f.E.E. Fenwick, Seismic behaviour of a reinforced concrete portal frame sustaining gravity loads. 1989. 22(1): p 39-49.

10.Peng, B.D., RP Fenwick, RC Carr, AJ Bull, DK, Analytical Model on Beam Elongation within the Reinforced Concrete Plastic Hinges. NZSEE Conference, 2007.

11.Peng, B.D., RP Fenwick, RC Carr, Athol Bull, DK, Modelling of $R C$ moment resisting frames with precast-prestressed flooring system. NZSEE Conference, 2009.

12.Bull, D.K., Understanding the complexities of designing diaphragms in buildings for earthquakes. Bulletin of the New Zealand Society for Earthquake Engineering, 2004. 37(2): p. 70-88.

13.Peng, B.H., et al., Experimental study on the seismic performance of $R C$ moment resisting frames with precast-prestressed floor units. 2008.

14.Matthews, J., Hollow-core floor slab performance following a severe earthquake. 2004

15.Nigel Priestley, M.J.P.J., The PRESSS Program-Current Status and Proposed Plans for Phase III. 1996. 41(2): p. 23.

16.Priestley, M.N.S., S Conley, James R Pampanin, Stefano \%J PCI journal, Preliminary results and conclusions from the PRESSS five-story precast concrete test building. 1999. 44(6): p. 42-67.

17.Matsuoka, T. and M. Ohkubo. Energy Dissipation Mechanism Controlled Bottom Rebar Yielding at Beam-end. in Summaries of technical papers of the Annual Meeting Architectural Institute of Japan. 1996.

18.Ohkubo, M., Matsuoka, T., Yoshioka, T., and Anderson, D. L., Shear transfer mechanism of reinforced concrete beams with a slot at the beamend. Proceedings of Japan Concrete Institute, 1999. 21(3): p. 523-528.

19.Au, E.V., The mechanics and design of a non-tearing floor connection using slotted reinforced concrete beams. University of Canterbury, Christchurch, New Zealand: University of Canterbury, 2010. p. 349.

20.Leslie, B.J., The Development and Validation of a Non-tearing Floor Precast Concrete Structural System for Seismic Regions. University of Canterbury, Christchurch, New Zealand, 2010.

21.Paulay, T. and M.N. Priestley, Seismic design of reinforced concrete and masonry buildings. University of California, Sun Diego, USA, 1992.

22.Mahini, S.S. and H.R. Ronagh, Web-bonded FRPs for relocation of plastic hinges away from the column face in exterior RC joints. Composite Structures, 2011. 93(10): p. 2460-2472. 
23.Oudah, F. and R. El-Hacha. Plastic Hinge Relocation using the RC SlottedBeam Column Connection. in 10th National Conference on Earthquake Engineering. 2014.

24.Oudah, F. and R. El-Hacha, Seismic performance of modified singleslotted-beam concrete connection. Journal of Earthquake Engineering, 2017. 21(5): p. 726-751.

25.Oudah, F. and R.J.P.o.t.C.I.R.I.P. El-Hacha, Development of double-slotted beam-column connections for the seismic design of structures. 2015.

26.Oudah, F. and R. El-Hacha, Plastic hinge relocation in concrete structures using the double-slotted-beam system. Bulletin of Earthquake Engineering, 2017. 15(5): p. 2173-2199.

27.Ohkubo, M. and T. Hamamoto. Developing reinforced concrete slotted beam structures to reduce earthquake damage and to enhance seismic structural performance. in Proceedings of the 13th annual world conference on earthquake engineering, Vancouver. 2004.

28.Byrne, J. and D. Bull, Design and testing of reinforced concrete frames incorporating the slotted beam detail. Bulletin of the New Zealand Society for Earthquake Engineering, 2012. 45(2): p. 77-83.

29.Lau, D.B.N., Influence of precast prestressed flooring on the seismic performance of reinforced concrete perimeter frame buildings. 2007, ResearchSpace@ Auckland.

30.Muir, C., D. Bull, and S. Pampanin, Preliminary observations from biaxial testing of a two-storey, two-by-one bay, reinforced concrete slotted beam superassembly. Bulletin of the New Zealand Society for Earthquake Engineering, 2012. 45(3): p. 97-104.

31.Muir, C., S. Pampanin, and D. Bull. Experimental method and results from seismic testing of a two-storey, two-by-one bay, reinforced concrete slotted beam superassembly. in Proceedings of the 15th World Conference on Earthquake Engineering (15WCEE), Lisbon, Portugal, September. 2012.

32.Muir, C., S. Pampanin, and D. Bull. Background, design and construction of a two-storey, two-by-one bay, reinforced concrete slotted beam superassembly. in Proceedings of the 15th World Conference on Earthquake Engineering (15WCEE). 2012.

33.Muir, C., D. Bull, and S. Pampanin. Seismic testing of the slotted beam detail for reinforced concrete structures. in Structures Congress 2013: Bridging Your Passion with Your Profession. 2013.

34.Muir, C.A., Seismic performance of the slotted beam detail in reinforced concrete moment resisting frames. 2014.

35.Amaris A., P.S., Bull D., and Carr A., Experimental investigation on a hybrid jointed precast frame with non-tearing floor connections. NZSEE Conference, 2008.

36.Golondrino, J.C.M., GA Chase, JG Rodgers, GW Clifton, CG. Clamping Force Effects on the Behaviour of Asymmetrical Friction Connections (AFC). in Proceedings of the 15th World Conference on Earthquake Engineering (15WCEE), Lisbon, Portugal, September. 2012.

37.Rodgers, G.W., Next generation structural technologies: implementing high force-to-volume energy absorbers. 2009.

38.Aldemir, A.J.J.o.t.F.o.E. and A.o.G. University, Effect of slot depth on the behavior of double-slotted reinforced concrete beam systems. 2018. 33(2): p. 659-669.

39.Oudah, F. and R.J.A.S.J. El-Hacha, Innovative Self-Centering Concrete Beam-Column Connection Reinforced Using Shape Memory Alloy. 2018. 115(3).

40.Oudah, F., R.J.S.M. El-Hacha, and Structures, Monolithic SMA-reinforced double slotted beam-column connection. 2020. 29(3): p. 035002.

41.Oudah, F. and R. El-Hacha, Damage and deformation assessment of earthquake-resistant RC slotted beam-column connections using digital image correlation technique. Engineering Structures, 2020. 215: p. 110442 . 